\title{
Parallel Effects of Methamphetamine on Anxiety and CCL3 in Humans and a Genetic Mouse Model of High Methamphetamine Intake
}

\author{
Marilyn Huckans ${ }^{a-d} \quad$ Clare J. Wilhelm ${ }^{a, b} \quad$ Tamara J. Phillips ${ }^{a, d}$, e \\ Elaine T. Huang ${ }^{a, d}$ Rebekah Hudson ${ }^{a}$ Jennifer M. Loftis ${ }^{a, b}, d$ \\ ${ }^{a}$ Research and Development Service, VA Portland Health Care System, Portland, OR, USA; ${ }^{b}$ Department of \\ Psychiatry, Oregon Health and Science University, Portland, OR, USA; ' Mental Health and Clinical Neurosciences \\ Division, VA Portland Health Care System, Portland, OR, USA; ${ }^{d}$ Methamphetamine Abuse Research Center, Oregon \\ Health and Science University, Portland, OR, USA; ${ }^{e}$ Department of Behavioral Neuroscience, Oregon Health and \\ Science University, Portland, OR, USA
}

\section{Keywords}

Methamphetamine · Anxiety · Rodents · Humans · Genetic model $\cdot$ Immune system $\cdot$ Hippocampus

\begin{abstract}
Background: Methamphetamine (MA) abuse causes immune dysfunction and neuropsychiatric impairment. The mechanisms underlying these deficits remain unidentified. Methods: The effects of MA on anxiety-like behavior and immune function were investigated in mice selectively bred to voluntarily consume high amounts of MA [i.e., MA high drinking (MAHDR) mice]. MA (or saline) was administered to mice using a chronic (14-day), binge-like model. Performance in the elevated zero maze (EZM) was determined 5 days after the last MA dose to examine anxiety-like behavior. Cytokine and chemokine expressions were measured in the hippocampus using quantitative polymerase chain reaction (qPCR). Human studies were also conducted to evaluate symptoms of anxiety using the General Anxiety Disorder-7 Scale in adults with and without a history of MA dependence. Plasma samples collected from human research participants were used for confirmatory analysis of murine qPCR results using an enzyme-linked immunosorbent assay. Results:
\end{abstract}

During early remission from MA, MAHDR mice exhibited increased anxiety-like behavior on the EZM and reduced expression of chemokine ( $\mathrm{C}-\mathrm{C}$ motif) ligand 3 ( $\mathrm{cCl} 3$ ) in the hippocampus relative to saline-treated mice. Human adults actively dependent on MA and those in early remission had elevated symptoms of anxiety as well as reductions in plasma levels of CCL3, relative to adults with no history of MA abuse. Conclusions: The results highlight the complex effects of MA on immune and behavioral function and suggest that alterations in CCL3 signaling may contribute to the mood impairments observed during remission from MA addiction.

(c) 2018 S. Karger AG, Basel

\section{Introduction}

Methamphetamine (MA) addiction is a debilitating disorder that causes neuropsychiatric and physiological impairments that make treatment and recovery efforts challenging. The neuropsychiatric impairments consequent to chronic MA abuse [1] are associated with worse treatment retention, outcomes, and heightened relapse rates [2-4]. In particular, MA abuse causes disruption of

\section{KARGER}

(C) 2018 S. Karger AG, Basel

E-Mail karger@karger.com

www.karger.com/nps
Jennifer M. Loftis, PhD

VA Portland Health Care System (R\&D16)

3710 SW US Veterans Hospital Rd.

Portland, OR 97239 (USA)

E-Mailloftisj@ohsu.edu; jennifer.loftis2@va.gov 
normal immune function both in the periphery and in the brain. MA abuse is associated with increased levels of eotaxin-1 (CCL11), matrix metalloproteinase-3, and reductions in C-reactive protein in the plasma of active or recently abstinent MA users [1]. Several mechanisms are hypothesized to contribute to the detrimental effects of MA on brain function, including compromise of the blood-brain barrier, hyperthermia, reactive oxygen species generation, production of inflammatory mediators by glia, inhibition of neurogenesis, and impaired bioenergetics [reviewed in 5,6]. How these alterations in the brain contribute to abuse potential and whether these changes differ due to genetic influences is unknown.

Production of inflammatory mediators is strongly associated with neuropsychiatric impairment, especially sickness-like behavior [reviewed in 7]. Potentially due to neuroimmune dysfunction, adults with current or recent histories of MA dependence exhibit increased anxiety, depression, and deficits in attention, memory, and executive function relative to controls, though there is significant individual variability $[1,8]$. Understanding this variability in humans is difficult, however, due to the frequent presence of comorbid disorders and polydrug use [8], as well as other challenges associated with human research. This study made use of the selectively bred MA high drinking (MAHDR) mouse line to expand on their utility as a model for the genetic risk for high MA intake [reviewed in 9] by examining the susceptibility to MA-induced psychological sequelae (e.g., mood impairment). MAHDR mice voluntarily consume MA in a 2-bottle choice procedure and operantly self-administer MA orally and intracerebroventricularly to a larger extent than MA low drinking (MALDR) mice [10]. Furthermore, the MAHDR line consumes binge-like levels of MA under conditions of high MA availability [11], making them a good model for human MA addiction.

Anxiety-like behavior and expression of immune mediators in the brain were examined following binge-like MA exposure or saline in MAHDR mice. Cytokine and chemokine expression were measured in the hippocampus, because this brain region is closely linked with several of the neuropsychiatric phenotypes observed in MA abuse, including anxiety, depression and memory [12], and because the hippocampus is a target of MA effects [13]. Expression of tumor necrosis factor-a (tnf) and interleukin-4 (il4) were used as markers of pro- and antiinflammatory signaling, respectively. Dysregulation of tnf and $i l 4$ has also been associated with depression [14]. Expression of the chemokines regulated on activation, normal $\mathrm{T}$ cell expressed and secreted (RANTES; ccl5) and chemokine (C-C motif) ligand 3 ( $c c l 3$ ) were examined because they regulate astrocyte, microglial, and neuronal function and are also involved in neurogenesis [15]. Neurogenesis is critical for learning and memory [16] and is also closely associated with anxiety [17].

Studies with human subjects paralleled animal studies and examined anxiety and plasma cytokine and chemokine expression in adults with and without a history of MA dependence. Our results suggest that MAHDR mice and humans exhibit parallel behavioral responses following MA exposure and identify novel MA-induced immune disruptions that may increase vulnerability to viral infections such as human immunodeficiency virus (HIV).

\section{Materials and Methods}

\section{Animals and MA Exposure}

Male MAHDR mice aged 8-10 weeks were used in these studies to parallel the high proportion of males observed in our human MA remission group. Mice were generated by the Methamphetamine Abuse Research Center Animal Core within the VA Portland Health Care System Veterinary Medical Unit. Experimental procedures were consistent with guidelines from the National Institutes of Health and approved by the VA Institutional Animal Care and Use Committee. The selectively bred MAHDR mouse line was derived from the $\mathrm{F} 2$ generation cross of the $\mathrm{C} 57 \mathrm{BL} / 6 \mathrm{~J}$ and $\mathrm{DBA} / 2 \mathrm{~J}$ inbred mouse strains. The selection has been repeated 4 times with highly replicable results, and selection procedures and results for the first 2 sets of lines have been fully described in previous publications $[18,19]$. The mice used in the current study were from replicates 2-4 from selection generations S4 and S5. They were group-housed (2-4 per cage) with littermates after weaning at $21 \pm 1$ days of age, and had ad libitum access to tap water and rodent block chow (Purina 5001 ${ }^{\mathrm{TM}}, 4.5 \%$ fat content; Animal Specialties Inc., Hubbard, OR, USA), except during testing. Treatment group mice were exposed to MA using a previously described chronic, binge-like MA treatment schedule [20], with all mice in a given cage receiving the same treatment (either MA or saline). This prevented the interaction of MA-intoxicated animals with nonintoxicated animals. Briefly, mice were injected (subcutaneously) 4 times per day with $10 \mathrm{mg} / \mathrm{kg}(+) \mathrm{MA}$ hydrochloride (Sigma-Aldrich, St. Louis, MO, USA), and control (CTL) animals received saline (0.9\% NaCl; Baxter Healthcare Corporation, Deerfield, IL, USA) injections at the same times. Each injection on a given day was separated by $2 \mathrm{~h}$, and the animals were returned to their home cages during the intervening times. Injections were administered every other day until the mice had received 7 total sets of daily injections (i.e., "binges" for the MA group) over a 14-day period.

\section{Elevated Zero Maze}

Anxiety-like behavior was examined in MAHDR mice during early recovery following the cessation of MA (or vehicle) exposure. Animals underwent behavioral assessments 5 days after the final dose of MA or saline. All testing was performed during the light phase of the 12-h/12-h light/dark cycle. Behavior in the elevated zero maze (EZM) was recorded and measured using the EthoVi-
$2 \quad$ Neuropsychobiology DOI: $10.1159 / 000485129$
Huckans/Wilhelm/Phillips/Huang/ Hudson/Loftis 
sion XT 10 video-tracking system (Noldus Information Technology Inc., Leesburg, VA, USA).

The EZM procedure for assessing anxiety-like behavior was based on previous studies [21-23]. The apparatus was positioned $51 \mathrm{~cm}$ off the ground and was a circular walkway (about $46 \mathrm{~cm}$ wide) divided into 4 sections. Two sections were enclosed by 11-cm-high transparent walls, whereas the other 2 were largely open areas that had $2-\mathrm{mm}$ tall lips to reduce the chance of falling from the walkway. During testing, the EZM was placed into a rubber pine chip bedding-lined bin so that if a mouse fell, it was contained and landed on a soft surface. Mice were individually placed on the walkway at the intersection of an open and closed section and allowed to freely explore the apparatus for $5 \mathrm{~min}$. The apparatus was cleaned with $70 \%$ ethanol and thoroughly dried before each trial. The time spent in open and closed areas, average velocity, and the number of transitions from open to closed sections were determined. Lighting conditions in the room averaged $260 \mathrm{~lx}$.

mRNA Extraction, cDNA Synthesis, and Real-Time

Polymerase Chain Reaction

A subset of the mice used in the EZM study, as well as a subset of identically dosed mice used in a study of novel object recognition were euthanized 5 days (mice tested using the novel object recognition test) or 6 days (mice tested using the EZM) after the last MA exposure via $\mathrm{CO}_{2}$ asphyxiation. Brains were rapidly removed, and hippocampi were microdissected and frozen at $-80^{\circ} \mathrm{C}$ until used. The hippocampus was chosen because of its demonstrated roles in affective behavior [24] and memory [25]. Brain tissue was homogenized in TRIzol and then pelleted. Supernatants were transferred to new 1.5-mL Eppendorf tubes, mixed with phenol chloroform and then separated into phases via centrifugation. The clear RNA phase was collected, precipitated in isopropanol (100\%, Thermo Fisher Scientific, Waltham, MA, USA), and pelleted. The RNA pellet was then washed with $75 \%$ ethanol, pelleted, allowed to air dry, and then resuspended in $50 \mu \mathrm{L}$ of DEPC water (Thermo Fisher Scientific, Waltham, MA, USA) and quantified. cDNA libraries were generated using the Superscript VILO cDNA Synthesis Kit (Thermo Fisher Scientific, Waltham, MA, USA) as per manufacturer directions. RNA $(1 \mu \mathrm{g})$ was added to the VILO reaction mix and SuperScript Enzyme mix with water to a total volume of $20 \mu \mathrm{L}$. The cDNA was generated by running the samples at $25^{\circ} \mathrm{C}$ for $10 \mathrm{~min}, 42^{\circ} \mathrm{C}$ for $60 \mathrm{~min}$, and $85^{\circ} \mathrm{C}$ for $5 \mathrm{~min}$ after which samples were stored at $-20^{\circ} \mathrm{C}$ until used. Targeted gene expression for il4 (forward: acaggagaagggacgccat, reverse: gaagccctacagacgagctca), $\operatorname{tnf}$ (forward: catcttctcaaaattcgagtgacaa, reverse: tgggagtagacaaggtacaaccc), ccl3 (forward: atgaaggtctccacc, reverse: ggcattcagttccag), ccl5 (forward: cagcagcaagtgctccaatctt, reverse: ttcttgaacccacttcttctctgg) and gapdh (forward: ggcatggactgtggt, reverse: ttcaccaccatggag) was measured using the Platinum SYBR Green quantitative polymerase chain reaction SuperMix-UDG (Thermo Fisher Scientific, Waltham, MA, USA). The cDNA was combined with SYBR green, ROX reference dye, primers, and DEPC water, with a holding cycle of $50^{\circ} \mathrm{C}$ for $2 \mathrm{~min}, 95^{\circ} \mathrm{C}$ for $2 \mathrm{~min}$, and $40 \mathrm{cycles}$ of $95^{\circ} \mathrm{C}$ for $15 \mathrm{~s}, 60^{\circ} \mathrm{C}$ for $30 \mathrm{~s}$, and a standard melt curve. Values were normalized to GAPDH expression and ROX passive reference dye, and the data are shown as $n$-fold change from the MAHDR CTL mice. Previous studies suggest that GAPDH is not regulated by MA treatment $24 \mathrm{~h}$ following exposure, though evidence of regulation was observed $6 \mathrm{~h}$ after MA treatment [26].

Translational Effects of MA on Behavior and Immune Function

\section{Human Research Participants}

Participants were recruited from Portland, OR, area addiction treatment centers and the community through word of mouth and via study advertisements posted in clinics, websites, and newspapers. Subjects were enrolled into 1 of 3 groups: (1) CTL group $(n=46)$ : adults with no lifetime history of dependence on any substance other than nicotine or caffeine; (2) MA-active (MA-ACT) group $(n=35)$ : adults actively using MA and currently meeting criteria for MA dependence; (3) MA remission (MA-REM) group $(n=49)$ : adults in early remission from MA dependence $\geq 1$ month and $\leq 12$ months. General exclusion criteria were history of a major medical illness or current use of medications that are likely to be associated with serious neurological or immune dysfunction [e.g., stroke, traumatic brain injury, HIV infection, hepatitis $\mathrm{C}$ virus infection, primary psychotic disorder, immunosuppressants, antivirals, or anti-tumor necrosis factor (TNF)- $\alpha$ agents]. Additional exclusion criteria for the CTL group were: (1) meets criteria for lifetime history of dependence on any substance (other than nicotine or caffeine dependence) based on the Diagnostic and Statistical Manual of Mental Disorders - Fourth Edition (DSM-IV) [27] with confirmation by the Mini International Neuropsychiatric Interview questionnaire (MINI) [28], (2) heavy alcohol use as defined by the National Institute on Alcohol Abuse and Alcoholism (women: average alcohol use $\geq 7$ standard drinks weekly for $\geq 1$ year; men: average alcohol use $\geq 14$ standard drinks weekly for $\geq 1$ year [29]), or (3) on the day of the study visits, tests positive on a urine drug analysis for any drug of abuse including alcohol. Additional inclusion criteria for the ACT group included: (1) meets DSM-IV [27] criteria for dependence on MA with confirmation by the MINI [28], (2) average MA use of $\geq 2$ days per week for $\geq 1$ year, and (3) last use of MA was $\leq 2$ weeks ago. Additional inclusion criteria for the REM group were all criteria for the ACT group, except last use of MA was $\geq 1$ and $\leq 12$ months ago, and on the day of the study visit, does not test positive on a urine drug analysis for any drugs of abuse including alcohol.

\section{Human Subjects Ethical Approval}

The protocol conformed to the ethical guidelines of the 1975 Declaration of Helsinki (6th revision, 2008) and was approved by the Institutional Review Boards at the VA Portland Health Care System and Oregon Health and Science University. Research participants gave informed consent after the procedures of the study had been explained in full.

\section{Human Study Procedures}

Participants were compensated with grocery store vouchers (USD 100) for completing the following procedures: clinical interview, urine drug analysis, hepatitis $\mathrm{C}$ virus and HIV antibody screening, blood sample collection, and a well-validated questionnaire to measure symptoms of anxiety, the General Anxiety Disorder-7 Scale (GAD-7) [30]. Responses to questionnaires were scored and rescored by separate study personnel, and all data were entered into a database that was double-checked by separate study personnel prior to analysis.

\section{Enzyme-Linked Immunosorbent Assay}

CCL3 was chosen for analysis in human samples, based on the animal results. Levels of CCL3 in human plasma samples were determined using an R\&D Systems (Minneapolis, MN, USA) enzyme-linked immunosorbent assay (ELISA) kit (DY270). The 
Table 1. Participant demographics and recency of drug use

\begin{tabular}{lccc}
\hline & $\begin{array}{l}\text { CTL } \\
(n=46)\end{array}$ & $\begin{array}{l}\text { MA-ACT } \\
(n=35)\end{array}$ & $\begin{array}{l}\text { MA-REM } \\
(n=49)\end{array}$ \\
\hline Age, years & $35.3(12.2)$ & $44.6(8.6)^{\mathrm{b}, \mathrm{d}}$ & $35.6(10.5)$ \\
Male, \% & 48 & 43 & $84^{\mathrm{b}, \mathrm{d}}$ \\
Caucasian, \% & 80 & 89 & 92 \\
White, $n$ & 37 & 31 & 45 \\
Nonwhite, $n$ & 9 & 4 & 4 \\
Years of education & $13.3(1.7)$ & $12.7(1.4)$ & $11.9(1.5)^{\mathrm{b}, \mathrm{c}}$ \\
Days since last MA use & $\mathrm{n} . \mathrm{a}$. & $0.5(1.1)$ & $133(167)$ \\
Body mass index & $28.9(6.9)$ & $25.8(4.3)^{\mathrm{a}}$ & $27.4(4.1)$ \\
Current tobacco use, \% & 17 & $83^{\mathrm{a}}$ & $84^{\mathrm{a}}$ \\
\hline
\end{tabular}

n.a. denotes a measure that was not relevant to that group. Unless otherwise indicated, figures are mean values with standard deviations in parentheses. ${ }^{\mathrm{a}} p<0.05,{ }^{\mathrm{b}} p<0.001$ vs. CTL; ${ }^{\mathrm{c}} p<0.05,{ }^{\mathrm{d}} p<0.001$ vs. MA-ACT.

ELISA was carried out as described in the manufacturer's protocol, with plasma samples assayed in duplicate. A standard curve was generated, and CCL3 levels were determined by fitting the standard curve to a fourth-order polynomial equation (range: 1-1,000 $\mathrm{pg} / \mathrm{mL})$.

\section{Statistical Analysis}

Data analyses and graphs were created with Prism 6.05 (GraphPad Software Inc., La Jolla, CA, USA) and IBM SPSS Statistics 22 (IBM Corporation, Armonk, NY, USA). The threshold for statistical significance was $p<0.05$. Analysis of variance (ANOVA) and analysis of covariance (ANCOVA), when appropriate, were used to compare across groups and treatments. The Fisher least squares difference test was used for a priori multiple comparisons. $\chi^{2}$ tests were conducted to compare proportions for dichotomous demographic and clinical variables [i.e., sex, ethnicity, tobacco use, and mental health status (GAD-7 score $<10$ vs. $\geq 10$ )]. Linear regression was used to compare the number of days since the last use of MA with plasma levels of CCL3. Data shown are means \pm standard error of the mean unless otherwise noted.

\section{Results}

\section{Human Sample Characteristics}

Participant demographic and clinical characteristics are presented in Table 1 . There was a significant age difference $[F(2,127)=9.40, p<0.001]$ between the MAACT group and both the MA-REM and the CTL groups, with the MA-ACT group being older than the other groups. Differences were also observed in the stratification of men and women across groups (Pearson $\chi^{2}=$ $18.57, p<0.001)$ with the MA-REM group having a higher proportion of males than females relative to the ACT and CTL groups. Group differences were observed in years of education $[F(2,127)=11.20, p<0.001]$, with the MA-REM group having less education than the CTL group and the MA-ACT group. The frequency of tobacco use across groups was also different (Pearson $\chi^{2}=52.68$, $p<0.001)$, with both the MA-ACT and the MA-REM groups being more likely to use tobacco than the CTL group. There was a significant main effect of group on body mass index $(\mathrm{BMI})[F(2,124)=4.17, p<0.05]$, with the MA-ACT group having a lower BMI than the CTL group.

Signs and Symptoms of Anxiety during Early Recovery from MA Exposure

During the EZM test, time spent in the open arms was used as an index of open space-induced anxiety-like behavior in mice. Mice exposed to MA spent significantly less time in the open arms of the apparatus relative to CTL mice (CTL $123 \pm 7$ s vs. MA $58 \pm 16 s ; p=0.001$ ). These data suggest that mice with a genetic propensity for increased MA consumption may also experience an increase in anxiety during abstinence from the drug (Fig. 1a). No differences in the number of crossovers from closed to open (CTL $27 \pm 3$ vs. MA $19 \pm 5$ crossovers per session; $p=0.14$ ) or mean velocity (CTL $3.7 \pm 0.2 \mathrm{~cm} / \mathrm{s}$ vs. MA $3.2 \pm 0.4 \mathrm{~cm} / \mathrm{s} ; p=0.28$ ) were observed between CTL and MA-treated mice.

In humans, a significant main effect of group was found for anxiety $[F(2,126)=20.38, p<0.0001]$, with subjects in the MA-ACT group having higher GAD-7 scores than either the CTL or MA-REM group, and the MA-REM group having higher scores than the CTL group (Fig. 2). Given some differences in participant demographics, ANCOVAs were carried out that adjusted for differences in age, education, BMI, sex, and/or tobacco use status. Inclusion of potential covariates did not alter the results (online suppl. Table 1; for all online suppl. material, see www.karger.com/doi/10.1159/000485129), with all analyses indicating that both the MA-ACT and MA-REM groups had higher GAD-7 scores than the CTL group. Using a threshold score of 10 , the GAD-7 has a sensitivity of $89 \%$ and a specificity of $82 \%$ for diagnosing generalized anxiety disorder $[30,31]$. When we applied this cutoff score to our human sample, there was a significant group difference for the proportion of individuals with GAD-7 scores of 10 or greater (Pearson $\chi^{2}=$ $19.25, p<0.001$ ), and a significantly greater proportion of individuals in the MA groups met this criterion, as compared to the CTL group. Specifically, 2 of 46 participants in the CTL group had GAD-7 scores of 10 or greater, while 16 of 35 participants in the MA-ACT group fit this 


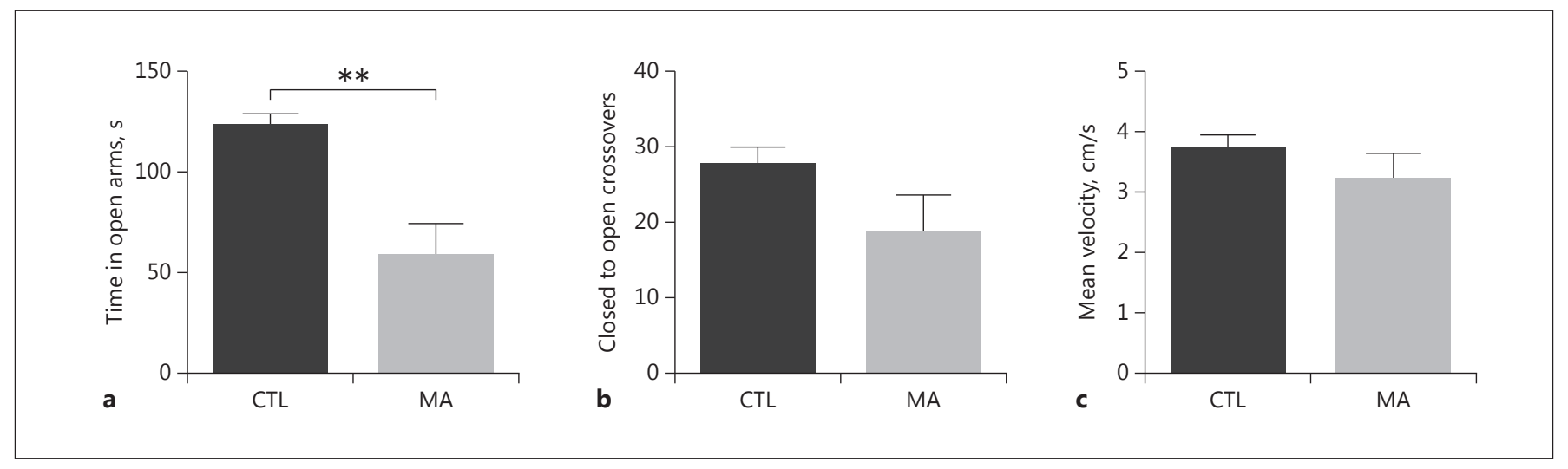

Fig. 1. MAHDR mice exhibit increased anxiety-like behavior following MA. a MA-exposed MAHDR mice spent less time in the open arms of the EZM, relative to saline-treated control MAHDR mice. MA- and saline-exposed MAHDR mice make a similar number of crossovers between the closed and open portions of the EZM (b) and exhibit a similar velocity (c) in the EZM. $n=8-9$ mice per group, tested in 2 passes of $4-5$ mice per group; ** $p<0.01$, unpaired $t$ test.

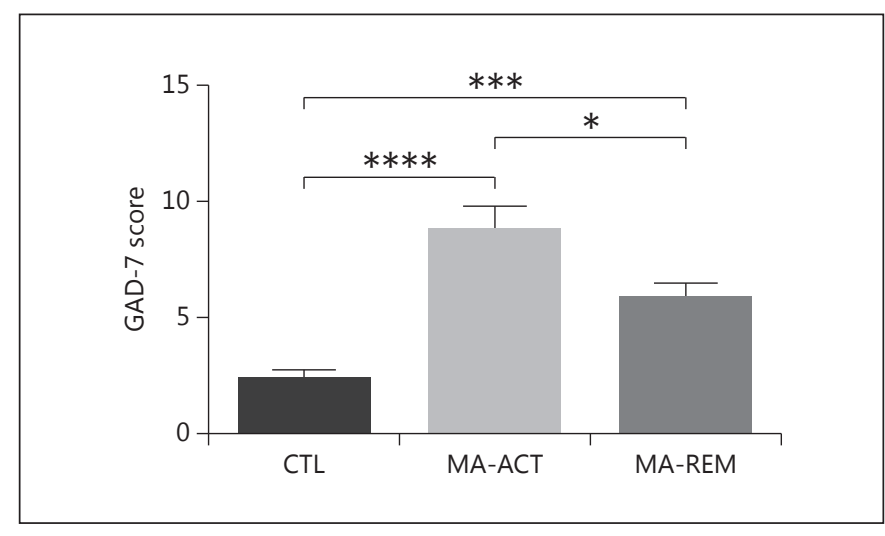

Fig. 2. Adults with a history of MA abuse exhibit increased anxiety, paralleling results for an animal line with high genetic susceptibility for MA intake. Adults in the MA-ACT and MA-REM groups reported increased anxiety as determined from the GAD-7 questionnaire relative to the CTL group. The ACT group also had increased anxiety relative to the REM group. ${ }^{*} p<0.05,{ }^{* * *} p<0.001$ using post hoc Sidak multiple comparisons.

criterion (Pearson $\chi^{2}=19.68, p<0.0001$ ), and 12 of 49 participants in the MA-REM group had scores of 10 or higher $\left(\chi^{2}=7.66, p=0.02\right)$. Although the percentage of adults screening positive for a potential generalized anxiety disorder decreased during remission from MA, the proportion of participants in the MA-ACT and MA-REM groups with GAD-7 scores of 10 or greater did not differ significantly.

Translational Effects of MA on Behavior and Immune Function

\section{Immune Factor Expression in Murine and Human Samples}

Gene expression of cytokine and chemokine transcripts was determined in the hippocampi of a subset of MAHDR mice from this study and a cohort that had undergone identical treatment, but behavioral testing in a novel object recognition task. Results from the 2 cohorts were combined for analyses because there were no significant differences across cohorts. An unpaired $t$ test of $c c l 3$ expression indicated a significant reduction in expression following MA exposure ( $p<0.05$; Fig. 3a). There were no significant effects of drug treatment for the expression of il4, ccl5, or $\operatorname{tnf}$ (online suppl. Fig. 1). To assess whether the effect of MA on $c c l 3$ expression was specific to mice bred to consume high amounts of MA, we measured hippocampal $c c l 3$ expression in MALDR mice (i.e., mice bred to consume low amounts of MA). A similar trend toward a reduction in $c c l 3$ expression was observed in the hippocampi of MALDR mice run in parallel; however, the reduction was not statistically significant $(p=$ 0.06; online suppl. Fig. 2).

To determine whether a history of MA exposure has a similar effect in humans, plasma levels of CCL3 were measured in research participants. One-way ANOVA found a significant main effect of group $[F(2,94)=3.81$, $p<0.05$ ], with the MA-ACT $(p<0.05)$ and MA-REM $(p<0.05)$ groups showing lower plasma CCL3 levels, relative to the CTL group (Fig. 3b). To explore whether plasma CCL3 levels exhibited any sign of recovering within the MA-REM group, a linear regression was performed 


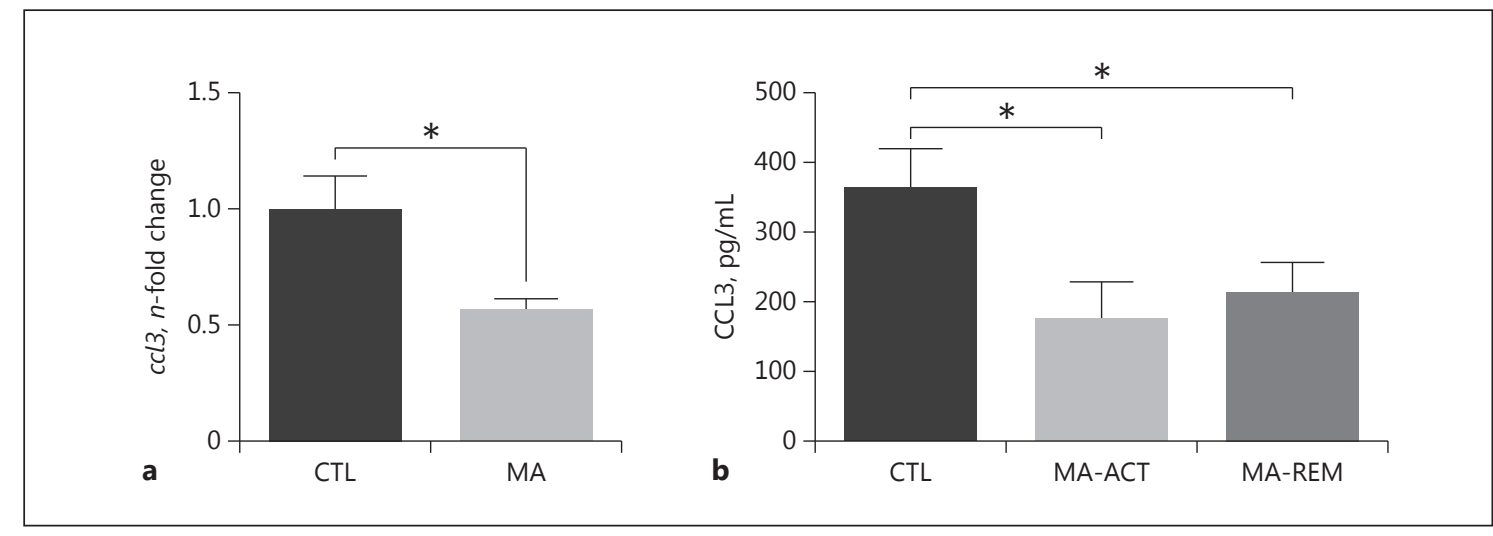

Fig. 3. MA exposure reduces $c c l 3$ expression in the mouse hippocampus and CCL3 concentration in human plasma. a MA exposure reduced levels of $c c l 3$ in the hippocampus in MAHDR mice ( $n=7$ mice per group). Gene expression results were normalized to GAPDH values, and the data are shown as $n$-fold change from the MAHDR CTL mice. ${ }^{*} p<0.05$ using an unpaired 2-tailed $t$ test. b Plasma levels of CCL3 were evaluated using ELISA. Adults actively dependent on MA and those in early remission had reductions in plasma levels of CCL3 relative to the CTL group. $* p<0.05$ using post hoc Sidak multiple comparisons.

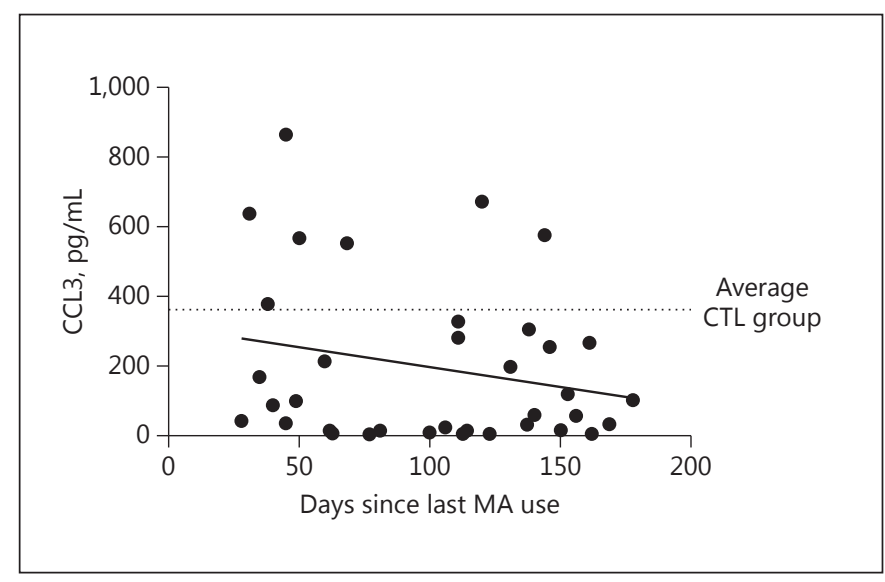

Fig. 4. In humans, plasma CCL3 concentration does not recover with abstinence. Plasma levels of CCL3 were plotted relative to each participant's reported number of days since last use of MA. No significant relationship between these parameters was observed, indicating that there was no evidence that CCL3 levels recovered following up to 180 days of abstinence. The dotted line represents the mean CCL3 concentration for the control (CTL) group $(362.18 \mathrm{pg} / \mathrm{mL})$. Linear regression: $r^{2}=0.05$, slope $=-1.14$, $p=0.18$.

comparing the reported "days since last use of MA" to plasma levels of CCL3. The slope of the regression was negative in this comparison, indicting no evidence of recovery in CCL3 levels during remission from MA dependence (Fig. 4).

\section{Discussion}

In this translational study, we used selectively bred MAHDR mice and human research participants to examine behavioral and immunological responses to MA. MAexposed animals exhibited increased anxiety-like behavior, similar to what was observed in humans both in the present study and previously [32-34]. In addition, this is the first study linking $\mathrm{ccl} 3$ with symptoms of anxiety. Binge-like MA-exposed MAHDR mice and humans with a history of MA abuse exhibited reductions in $c c l 3$ expression or plasma CCL3 levels, compared to controls. A trend toward reduced $\mathrm{ccl} 3$ expression was also observed in MALDR mice, suggesting that differences in genetic risk for MA use may not strongly influence the MA-mediated reduction in $c c l 3$. Nonetheless, the significant result in MAHDR mice supports their usefulness as a model for examining behavioral and neuroimmunological effects of MA that are relevant to MA use disorders.

Our study adds to a growing body of literature linking MA use and dependence with immune dysregulation and behavioral dysfunction in humans and rodents [reviewed in 35]. Studies in humans with clinical depression have observed increases in serum CCL3 levels and symptoms of depression [36,37], which contrasts with the current findings of reductions in hippocampal expression of $c c l 3$ and plasma CCL3 following MA in mice and humans. Similarly, cocaine downregulates macrophage inflammatory protein- $1 \beta$ [also known as chemokine ( $\mathrm{C}-\mathrm{C}$ motif) ligand 
4, CCL4; CCL3 and CCL4 are members of the $\beta$-chemokine family] [38]. This suggests that MA and other psychostimulants may exert unique effects on immune function and neuropsychiatric dysfunction. Reduced CCL3 in the periphery may have important implications for recruitment of immune cells, especially macrophages and neutrophils, to sites of injury or infection $[39,40]$. Decreased infiltration of immune cells may also contribute to slower wound healing associated with MA use [41]. Peripheral inflammation is known to play a role in mental health as we and others have described [1, 7, 42, 43]. Inflammation-induced mental dysfunction is most clearly observed in conditions such as cancer or hepatitis, where patients are treated with a pro-inflammatory mediator such as interferon- $\alpha[42,44-$ 46], and, more recently, in the context of substance use disorders $[1,47,48]$. Thus, reduced CCL3 may lead to slower wound healing, thereby resulting in persistent infection and a prolonged period of inflammatory signaling, which may result in ongoing symptoms of depression, anxiety and memory impairment.

Several studies suggest CCL3 influences cognitive function and hippocampal plasticity [49-51]. In a cell culture model system, norepinephrine reduces CCL3 release induced by lipopolysaccharide via activation of $\beta$-adrenergic receptors [52], and catecholamines, including norepinephrine, are key targets of MA effects [53]. In addition, deletion of $c c l 3$ was associated with decreased alcohol preference and consumption in mice in a 2-bottle choice paradigm [54]; MA consumption has not been studied in mice lacking $\mathrm{ccl}$. Astrocytes as well as neurons and microglia in seizure models produce CCL3 $[55,56]$. In the current study, 2 weeks of binge-like MA exposure led to a reduction in hippocampal $c c l 3$ expression in MAHDR mice, an effect which was paralleled in the periphery of adults actively dependent on MA and those in early remission from MA dependence. Future studies will examine whether peripheral plasma CCL3 is reduced in mice following an MA binge regimen, or whether this only occurs with prolonged MA abuse as observed in humans. Plasma levels of CCL3 had not recovered as long as 6 months after MA abuse, though a within-subject examination of CCL3 levels during recovery from MA abuse is needed. Our studies using a different animal model (low-dose MA treatment) found an increase in plasma and hippocampal CCL3 within $72 \mathrm{~h}$ of MA treatment and recovery of CCL3 levels after 3 weeks of abstinence [57]; however, it would be exciting to study this in our model of binge-level voluntary MA use [11]. In previous work, $4 \mathrm{~h}$ after a single $2 \mathrm{mg} / \mathrm{kg}$ dose of MA, the oppositely selectively bred low MA drinking MALDR mice exhibited reduced expression of $\mathrm{ccl} 3$ in the nucleus accum-

Translational Effects of MA on Behavior and Immune Function bens, as compared to saline-treated MALDR mice [18]. In humans, we did not observe a difference in CCL3 levels between active and abstinent MA use (average duration of reported abstinence $=53.3 \pm 24.4$ days). Furthermore, in humans recovering from MA dependence, we observed that higher plasma levels of CCL3, CCL4 (macrophage inflammatory protein-1 $\beta$ ), and monocyte chemoattractant protein-1 were significantly correlated with worse language fluency [57], but group differences between MA and CTL groups were nonsignificant for CCL3. Collectively, our results suggest that CCL3 may be particularly sensitive to MA - given the variability in CCL3 concentration depending on dose, duration of exposure, and length of abstinence.

In humans, plasma levels of CCL3 are reduced in adults with hepatitis $\mathrm{C}$ virus compared to adults without infection [58]. Our in vivo findings are consistent with in vitro experiments, which show that expression of $c c l 3$ is reduced in cultured dendritic cells treated with MA [59]. This is important because CCL 3 competes with HIV-1 for binding to the coreceptor CCR5, and it is the binding of HIV-1 to CCR5 that facilitates infection. Therefore downregulation of $c c l 3$ in adults with a history of MA abuse may increase the availability of CCR5, resulting in more efficient infection by HIV-1 [59]. In support of this hypothesis, HIV-1 infection is high in adults with MA use disorders [60], and HIV-infected subjects with certain ccl3 polymorphisms exhibit larger impairments in learning and memory compared with HIV-negative subjects [61]. Overall, our findings combined with the existing literature suggest that CCL3 is an important target of MA effects and represents a key molecule that interfaces between the immune system and neuropsychiatric outcomes (e.g., anxiety, depression, cognition).

Our study was limited to identifying associations between MA dependence, behavioral impairments, and chemokine dysregulation and does not establish causality. In addition, this study was not designed to examine the association between MA dependence and HIV-1, as HIV infection was an exclusion criterion. Our study is strengthened by the use of strict inclusion and exclusion criteria which resulted in a well-matched study cohort. We also present parallel observations in human and animal studies that reinforce the association between MA use and behavioral and immune impairments. Some have hypothesized that chemokines such as CCL3 are a major communication system in the brain [62]. Dysregulation of CCL3 by MA may be an important regulator of behavioral and immunological deficits induced by MA and may increase rates of HIV infection in adults using MA. 


\section{Acknowledgments}

The authors would like to thank the study participants and staff at each of the recruitment sites and Patricia Newman for study coordination. This work was supported in part by VA Merit Review Awards No. 1I01BX002061 (to J.M.L.) and No. I01BX002106 (to T.J.P.) from the United States Department of Veterans Affairs Biomedical Laboratory Research and Development and by NIH/ NIDA grants No. RC1DA028537 (to J.M.L., M.H.) and No. P50DA018165 (to J.M.L., M.H., T.J.P.), and by NIH/NIAAA grant No. P60AA010960 (to T.J.P.). Animals for this study were provided by the Portland Methamphetamine Abuse Research Center Animal Core NIH/NIDA grant No. P50DA018165 (to T.J.P.).

\section{Disclosure Statement}

No conflict of interest declared.

\section{Author Contributions}

All authors made significant contributions to the conduct (R.H., E.T.H.), design (M.H., J.M.L.), data analysis (C.W., J.M.L., T.J.P.), or preparation of the manuscript (M.H., C.W., T.J.P., E.T.H., R.B., J.M.L.). All authors have read and approved the final submitted version of the paper.

\section{References}

1 Huckans M, Fuller BE, Chalker AL, Adams M, Loftis JM: Plasma inflammatory factors are associated with anxiety, depression, and cognitive problems in adults with and without methamphetamine dependence: an exploratory protein array study. Front Psychiatry 2015;6:178.

2 Aharonovich E, Nunes E, Hasin D: Cognitive impairment, retention and abstinence among cocaine abusers in cognitive-behavioral treatment. Drug Alcohol Depend 2003;71:207211.

-3 Fals-Stewart W, Schafer J: The relationship between length of stay in drug-free therapeutic communities and neurocognitive functioning. J Clin Psychol 1992;48:539-543.

-4 Sadek JR, Vigil O, Grant I, Heaton RK, Group $\mathrm{H}$ : The impact of neuropsychological functioning and depressed mood on functional complaints in HIV-1 infection and methamphetamine dependence. J Clin Exp Neuropsychol 2007;29:266-276.

5 Salamanca SA, Sorrentino EE, Nosanchuk JD, Martinez LR: Impact of methamphetamine on infection and immunity. Front Neurosci 2014;8:445.

6 Loftis JM, Janowsky A: Neuroimmune basis of methamphetamine toxicity. Int Rev Neurobiol 2014;118:165-197.

-7 Dantzer R, O’Connor JC, Lawson MA, Kelley KW: Inflammation-associated depression: from serotonin to kynurenine. Psychoneuroendocrinology 2011;36:426-346.

8 McKetin R, Dawe S, Burns RA, Hides L, Kavanagh $\mathrm{DJ}$, Teesson $\mathrm{M}, \mathrm{McD}$ Young $\mathrm{R}$, Voce A, Saunders JB: The profile of psychiatric symptoms exacerbated by methamphetamine use. Drug Alcohol Depend 2016;161:104109.

-9 Phillips TJ, Shabani S: An animal model of differential genetic risk for methamphetamine intake. Front Neurosci 2015;9:327

10 Shabani S, Dobbs LK, Ford MM, Mark GP, Finn DA, Phillips TJ: A genetic animal model of differential sensitivity to methamphetamine reinforcement. Neuropharmacology 2012;62:2169-2177.
11 Shabani S, Houlton SK, Hellmuth L, Mojica E, Mootz JR, Zhu Z, Reed C, Phillips TJ: A mouse model for binge-level methamphetamine use. Front Neurosci 2016;10:493.

12 Valero J, Mastrella G, Neiva I, Sanchez S, Malva JO: Long-term effects of an acute and systemic administration of LPS on adult neurogenesis and spatial memory. Front Neurosci 2014;8:83.

13 Recinto P, Samant AR, Chavez G, Kim A, Yuan CJ, Soleiman M, Grant Y, Edwards S, Wee S, Koob GF, George O, Mandyam CD: Levels of neural progenitors in the hippocampus predict memory impairment and relapse to drug seeking as a function of excessive methamphetamine self-administration. Neuropsychopharmacology 2012;37:1275-1287.

14 Haji N, Mandolesi G, Gentile A, Sacchetti L, Fresegna D, Rossi S, Musella A, Sepman H, Motta C, Studer V, De Chiara V, Bernardi G, Strata P, Centonze D: TNF-alpha-mediated anxiety in a mouse model of multiple sclerosis. Exp Neurol 2012;237:296-303.

15 Whitney NP, Eidem TM, Peng H, Huang Y, Zheng JC: Inflammation mediates varying effects in neurogenesis: relevance to the pathogenesis of brain injury and neurodegenerative disorders. J Neurochem 2009;108:1343-1359.

16 Van Praag H, Christie BR, Sejnowski TJ, Gage FH: Running enhances neurogenesis, learning, and long-term potentiation in mice. Proc Natl Acad Sci USA 1999;96:13427-13431.

-17 Snyder JS, Soumier A, Brewer M, Pickel J, Cameron HA: Adult hippocampal neurogenesis buffers stress responses and depressive behaviour. Nature 2011;476:458-461.

18 Wheeler JM, Reed C, Burkhart-Kasch S, Li N, Cunningham CL, Janowsky A, Franken FH, Wiren KM, Hashimoto JG, Scibelli AC, Phillips TJ: Genetically correlated effects of selective breeding for high and low methamphetamine consumption. Genes Brain Behav 2009;8:758-771.

19 Shabani S, McKinnon CS, Reed C, Cunningham CL, Phillips TJ: Sensitivity to rewarding or aversive effects of methamphetamine determines methamphetamine intake. Genes Brain Behav 2011;10:625-636.
20 Loftis JM, Wilhelm CJ, Vandenbark AA, Huckans M: Partial MHC/neuroantigen peptide constructs: a potential neuroimmunebased treatment for methamphetamine addiction. PLoS One 2013;8:e56306.

21 Shepherd JK, Grewal SS, Fletcher A, Bill DJ, Dourish CT: Behavioural and pharmacological characterisation of the elevated "zeromaze" as an animal model of anxiety. Psychopharmacology (Berl) 1994;116:56-64.

22 Kulkarni SK, Singh K, Bishnoi M: Elevated zero maze: a paradigm to evaluate antianxiety effects of drugs. Methods Find Exp Clin Pharmacol 2007;29:343-348.

-23 Barkley-Levenson AM, Crabbe JC: Genotypic and sex differences in anxiety-like behavior and alcohol-induced anxiolysis in High Drinking in the Dark selected mice. Alcohol 2015;49:29-36.

24 Chesnokova V, Pechnick RN, Wawrowsky K Chronic peripheral inflammation, hippocampal neurogenesis, and behavior. Brain Behav Immun 2016;58:1-8.

25 Olsen RH, Allen CN, Derkach VA, Phillips TJ, Belknap JK, Raber J: Impaired memory and reduced sensitivity to the circadian period lengthening effects of methamphetamine in mice selected for high methamphetamine consumption. Behav Brain Res 2013;256:197-204.

26 Thomas DM, Francescutti-Verbeem DM, Liu X, Kuhn DM: Identification of differentially regulated transcripts in mouse striatum following methamphetamine treatment - an oligonucleotide microarray approach. J Neurochem 2004;88:380-393.

27 American Psychiatric Association: Diagnostic and Statistical Manual of Mental Disorders: DSM-IV-TR. Washington, American Psychiatric Association, 2000.

28 Sheehan DV, Lecrubier Y, Sheehan KH, Amorim P, Janavs J, Weiller E, Hergueta T, Baker R, Dunbar GC: The Mini-International Neuropsychiatric Interview (M.I.N.I.): the development and validation of a structured diagnostic psychiatric interview for DSM-IV and ICD-10. J Clin Psychiatry 1998;59(suppl 20):22-33; quiz 34-57. 
29 US Department of Health and Human Services: Rethinking drinking. How much is too much? https://www.rethinkingdrinking.niaaa. nih.gov/How-much-is-too-much/Is-yourdrinking-pattern-risky/Whats-At-Risk-OrHeavy-Drinking.aspx.

-30 Spitzer RL, Kroenke K, Williams JB, Lowe B: A brief measure for assessing generalized anxiety disorder: the GAD-7. Arch Intern Med 2006;166:1092-1097.

-31 Kroenke K, Spitzer RL, Williams JB, Monahan PO, Lowe B: Anxiety disorders in primary care: prevalence, impairment, comorbidity, and detection. Ann Intern Med 2007;146: 317-325.

- 32 Soderpalm A, Nikolayev L, de Wit H: Effects of stress on responses to methamphetamine in humans. Psychopharmacology (Berl) 2003; 170:188-199.

33 Mahoney JJ 3rd, Thompson-Lake DG, Cooper K, Verrico CD, Newton TF, De La Garza R 2nd: A comparison of impulsivity, depressive symptoms, lifetime stress and sensation seeking in healthy controls versus participants with cocaine or methamphetamine use disorders. J Psychopharmacol 2015;29:50-56.

-34 Mantsch JR, Baker DA, Funk D, Le AD, Shaham Y: Stress-induced reinstatement of drug seeking: 20 years of progress. Neuropsychopharmacology 2016;41:335-356.

-35 Stuart MJ, Baune BT: Chemokines and chemokine receptors in mood disorders, schizophrenia, and cognitive impairment: a systematic review of biomarker studies. Neurosci Biobehav Rev 2014;42:93-115.

- 36 Merendino RA, Di Pasquale G, De Luca F, Di Pasquale L, Ferlazzo E, Martino G, Palumbo MC, Morabito F, Gangemi S: Involvement of fractalkine and macrophage inflammatory protein-1 alpha in moderate-severe depression. Mediators Inflamm 2004;13:205-207.

- 37 Simon NM, McNamara K, Chow CW, Maser RS, Papakostas GI, Pollack MH, Nierenberg AA, Fava M, Wong KK: A detailed examination of cytokine abnormalities in major depressive disorder. Eur Neuropsychopharmacol 2008; 18:230-233.

- 38 Nair MP, Chadha KC, Hewitt RG, Mahajan S, Sweet A, Schwartz SA: Cocaine differentially modulates chemokine production by mononuclear cells from normal donors and human immunodeficiency virus type 1 -infected patients. Clin Diagn Lab Immunol 2000;7:96100.

39 Huffnagle GB, Strieter RM, McNeil LK, McDonald RA, Burdick MD, Kunkel SL, Toews GB: Macrophage inflammatory protein-1alpha (MIP-1alpha) is required for the efferent phase of pulmonary cell-mediated immunity to a Cryptococcus neoformans infection. J Immunol 1997;159:318-327.

40 DiPietro LA, Burdick M, Low QE, Kunkel SL, Strieter RM: MIP-1alpha as a critical macrophage chemoattractant in murine wound repair. J Clin Invest 1998;101:1693-1698.
41 Mihu MR, Roman-Sosa J, Varshney AK, Eugenin EA, Shah BP, Ham Lee H, Nguyen LN, Guimaraes AJ, Fries BC, Nosanchuk JD, Martinez LR: Methamphetamine alters the antimicrobial efficacy of phagocytic cells during methicillin-resistant Staphylococcus aureus skin infection. MBio 2015;6:e01622-15.

42 Loftis JM, Hauser P: The phenomenology and treatment of interferon-induced depression. J Affect Disord 2004;82:175-190.

43 Loftis JM, Patterson AL, Wilhelm CJ, McNett H, Morasco BJ, Huckans M, Morgan T, Saperstein S, Asghar A, Hauser P: Vulnerability to somatic symptoms of depression during interferon-alpha therapy for hepatitis C: a 16week prospective study. J Psychosom Res 2013;74:57-63.

44 Reuter K, Albrecht K, Seelig H, Meiss F, Mauch C, Kreuzberg N, Nashan D: Healthrelated quality of life, fatigue, and depression under low-dose IFN-alpha therapy in melanoma patients. J Immunother 2014;37:461467.

45 Musselman DL, Lawson DH, Gumnick JF, Manatunga AK, Penna S, Goodkin RS, Greiner K, Nemeroff CB, Miller AH: Paroxetine for the prevention of depression induced by high-dose interferon alfa. N Engl J Med 2001; 344:961-966.

46 Friebe A, Horn M, Schmidt F, Janssen G, Schmid-Wendtner $\mathrm{MH}$, Volkenandt $\mathrm{M}$, Hauschild A, Goldsmith CH, Schaefer M: Dose-dependent development of depressive symptoms during adjuvant interferon- $\alpha$ treatment of patients with malignant melanoma. Psychosomatics 2010;51:466-473.

47 Neupane SP: Neuroimmune interface in the comorbidity between alcohol use disorder and major depression. Front Immunol 2016; $7: 655$.

48 Araos P, Pedraz M, Serrano A, Lucena M, Barrios V, Garcia-Marchena N, CamposCloute R, Ruiz JJ, Romero P, Suarez J, Baixeras E, de la Torre R, Montesinos J, Guerri C, Rodriguez-Arias M, Minarro J, MartinezRiera R, Torrens M, Chowen JA, Argente J, Mason BJ, Pavon FJ, Rodriguez de Fonseca F: Plasma profile of pro-inflammatory cytokines and chemokines in cocaine users under outpatient treatment: influence of cocaine symptom severity and psychiatric co-morbidity. Addict Biol 2015;20:756-772.

49 Roberson R, Kuddo T, Horowitz K, Caballero $\mathrm{M}$, Spong CY: Cytokine and chemokine alterations in Down syndrome. Am J Perinatol 2012;29:705-708.

50 Kuijpers M, van Gassen KL, de Graan PN, Gruol D: Chronic exposure to the chemokine CCL3 enhances neuronal network activity in rat hippocampal cultures. J Neuroimmunol 2010;229:73-80.

51 Marciniak E, Faivre E, Dutar P, Alves Pires C, Demeyer D, Caillierez R, Laloux C, Buee L, Blum D, Humez S: The chemokine MIP-1alpha/CCL3 impairs mouse hippocampal synaptic transmission, plasticity and memory. Sci Rep 2015;5:15862.
52 Hasko G, Shanley TP, Egnaczyk G, Nemeth ZH, Salzman AL, Vizi ES, Szabo C: Exogenous and endogenous catecholamines inhibit the production of macrophage inflammatory protein (MIP) 1 alpha via a beta adrenoceptor mediated mechanism. Br J Pharmacol 1998; 125:1297-1303.

53 Eshleman AJ, Carmolli M, Cumbay M, Martens CR, Neve KA, Janowsky A: Characteristics of drug interactions with recombinant biogenic amine transporters expressed in the same cell type. J Pharmacol Exp Ther 1999; 289:877-885.

54 Blednov YA, Bergeson SE, Walker D, Ferreira VM, Kuziel WA, Harris RA: Perturbation of chemokine networks by gene deletion alters the reinforcing actions of ethanol. Behav Brain Res 2005;165:110-125.

55 Johnson EA, Dao TL, Guignet MA, Geddes CE, Koemeter-Cox AI, Kan RK: Increased expression of the chemokines CXCL1 and MIP$1 \alpha$ by resident brain cells precedes neutrophil infiltration in the brain following prolonged soman-induced status epilepticus in rats. J Neuroinflammation 2011;8:41.

56 Subileau EA, Rezaie P, Davies HA, Colyer FM, Greenwood J, Male DK, Romero IA: Expression of chemokines and their receptors by human brain endothelium: implications for multiple sclerosis. J Neuropathol Exp Neurol 2009;68:227-240.

-57 Loftis JM, Choi D, Hoffman W, Huckans MS Methamphetamine causes persistent immune dysregulation: a cross-species, translational report. Neurotox Res 2011;20:59-68.

-58 Huckans M, Fuller BE, Olavarria H, Sasaki AW, Chang M, Flora KD, Kolessar M, Kriz D, Anderson JR, Vandenbark AA, Loftis JM: Multi-analyte profile analysis of plasma immune proteins: altered expression of peripheral immune factors is associated with neuropsychiatric symptom severity in adults with and without chronic hepatitis $\mathrm{C}$ virus infection. Brain Behav 2014;4:123-142.

59 Nair MP, Saiyed ZM: Effect of methamphetamine on expression of HIV coreceptors and CC-chemokines by dendritic cells. Life Sci 2011;88:987-994.

60 Molitor F, Truax SR, Ruiz JD, Sun RK: Association of methamphetamine use during sex with risky sexual behaviors and HIV infection among non-injection drug users. West J Med 1998;168:93-97.

61 Levine AJ, Reynolds S, Cox C, Miller EN, Sinsheimer JS, Becker JT, Martin E, Sacktor N; Neuropsychology Working Group of the Multicenter AIDS Cohort Study: The longitudinal and interactive effects of HIV status, stimulant use, and host genotype upon neurocognitive functioning. J Neurovirol 2014; 20:243-257.

62 Adler MW, Geller EB, Chen X, Rogers TJ: Viewing chemokines as a third major system of communication in the brain. AAPS J 2006; 7:E865-E870.
Translational Effects of MA on Behavior and Immune Function 